\title{
"Generalizability" as Recognition: Reflections on a Foundational Problem in Qualitative Research
}

\author{
Charlotte Delmar
}

\begin{abstract}
The aim of the article is to develop what counts as "generalizability" in qualitative research. By taking an ontological and epistemic stance in relation to the four foundational problems: 1)Knowledge and its various forms. 2) Properties of reality and the doubleness of the situation. 3) How is understanding possible? 4) The researcher's role: What are the fundamental questions that the researcher must ask himself before a study is designed? we are able to approach the exploration of "generalizability" in qualitative research. Methodological theorists agree that the question of applicability is essential in the discussion of "generalizability" in qualitative research. If the quantitative tradition's requirement for replicability also has to be met, the pressing question during the article is what counts as replicability and applicability in qualitative research. In the exploration of what is involved in "generalizability" in qualitative research a combination of Gadamer and Flyvbjerg's thinking are important sources for a reflection on the ontological and epistemic questions related to the four foundational problems. The ontological question of what establishes a situation is an essential interpretation for the finding. A situation is characterised by its quality of doubleness: it is unique and typical at the same time. People with each their unique story and life world constitute the uniqueness of the situation. And a situation is typical in the sense that fundamental experiences can be found in every situation. The typical is what we as people have in common. There will be typical traits and recogizable patterns in every situation. The finding show us that "generalizability" in qualitative research builds on recognisability and a challenge to practice as a practical reasoning.
\end{abstract}

Keywords: Generalizability, recognisability, replicability, applicability, qualitative research, situation

Please cite this article as:

Delmar, C. (2010). "Generalizability" as Recognition: Reflections on a Foundational Problem in Qualitative Research. Qualitative Studies, 1(2): 115-128.

\section{Introduction}

The aim of the article is to illuminate ontological and epistemic questions encircling the answer of what counts as "generalizability" in qualitative research. For researchers concerned with the meaningfulness and significance of life in the form of people's deliberations, experiences, decisions and actions, this should be particularly important since the conceptual context in which their research is executed is typically a practice context with different changeable factors.

Replicability is paramount as generalizability in quantitative research but repetition with changeable factors in a practice context seems not to be the answer in qualitative research. By discussing the following four foundational problems, the article will reflect on the question of replicability and practical application in qualitative research.

- Knowledge and its various forms 
- Properties of reality and the doubleness of the situation

- How is understanding possible?

- The researcher's role: What are the fundamental questions that the researcher must ask himself before a study is designed?

The stimulus for writing this article comes from working in a health profession in which a number of different paradigms are at play. Which paradigm is deemed to be relevant for a specific research project will depend on whether the object of study concerns prognosis, diagnosis, treatment or nursing. The complexity of health scientific research is seen by the fact that it employs both tried and tested biomedical and epidemiological research methods, a large variety of qualitative methods, and methods that are still being developed, such as mixed methods (Wheeldon 2010, Creswell 2003). Research projects that focus on meaningfulness and significance of life in its various forms expressed in people's experiences require qualitative approaches and procedures. If, on the other hand, the research interest focuses on causal regularities based on the biological aspects of human nature, quantitative approaches and procedures are required. Irrespective of the type of research project it always requires approaches and procedures that 1) respect the studied phenomena and are 2) capable of producing new, research-founded knowledge.

The first condition for producing valid research is thus that the methodology is adapted to the specific object of examination. This is a self-evident and increasingly trivial statement, but why is it then that problems continue to arise in the generation of new knowledge? There may be a multitude of reasons for this, and at every point in the research process, poor choices may cast doubt on the value and validity of the knowledge generated.

The concept of "generalizability" in qualitative research is beset by indistinctness. In my experience of assessing nursing professional projects for financial support, the concept seems to have become increasingly indistinct and ill-defined in these types of projects, which stems from the pursuit of a form of generalizability that properly belongs to the natural sciences at the expense of the quality and validity of qualitative research. So there is cause for concern. Let me give a few experienced examples from my financial work concerning the projects combining quantitative and qualitative methods:

- The number of interviews undertaken in qualitative research studies has shown a steady, but unmotivated, growth.

- Concepts belonging to the natural sciences, such as effect, generalizability, bias, etc., are being used in qualitative research.

- Rather insufficient descriptions of the very complicated issue of qualitative research are seen, e.g. when only 10-15 lines out of a 5-page project description concern this aspect.

- The research irrespective of its distinct objects of knowledge is judged according to the same epistemic scientific criteria belonging to the natural sciences, such as generalizability. One of 
the problems is that qualitative research may be deemed less evident, or, even worse, unscientific.

This article therefore aims to guide the qualitative researcher by asking questions that may also stimulate an exploration of the question of "generalizability" in qualitative research. While this is by no means an exhaustive discussion but an attempt at a systematic identification of criteria for "generalizability" in qualitative research, the exploration takes an ontological and epistemic approach by asking questions that so to speak come before the logic inherent to the research. In doing so, it discusses the four foundational problems mentioned above.

\section{Background}

There seems to be a common perception among researchers in the qualitative tradition that generalizability in qualitative research is neither important, attainable nor relevant in relation to the objectives of research (Schoefield 2002, Kitto et al. 2008). As opposed to quantitative research, in which the principle of replicability is paramount, the sheer number of individual and conceptual components in qualitative studies is so large that a piecemeal repetition of each appears to be a hopeless task (Schoefield 2002).

We find work by Stake (1978), Guba \& Lincoln (1981, 1982) and Goetz \& LeCompte (1982) among the first important contributions to the discussion of generalizability in qualitative research. It was Stake's position that it is not feasible to apply a single case and generalize its results to a larger population, even when that case constitutes a subset of the population. He introduced the concept of "naturalistic generalizability", which enables the transfer of results from one study for the interpretation of similar situations. To achieve this, it is necessary to apply not only explicit comparisons between situations but also "tacit knowledge" based on personal experience. Generalizability will thus be based on the way things are and will lead to "expectability" rather than the predictability that characterizes quantitative research (Stake 1978, Schoefield 2002).

Guba \& Lincoln $(1981,1982)$ posited that as human activity is determined by context and time, we should rather talk about "fittingness", which is to say that the analysis attempts to establish the extent to which the studied situation matches other situations or problems which we want to study. Goetz \& LeCompte (1982) took a similar position. They argued that the results of qualitative studies can be used as a basis for comparison with other situations through what they termed "comparability" and "translatability". The former reflects how well-described and well-defined the components of a study are. These components include e.g. the unit of analysis, the concept development, the characteristics of the studied object and the framework in which the research is conducted. For a study to be "translatable", it must give a clear description of its theoretical position and the techniques or methods applied in research. In other words, the reporting of the research should be sufficiently detailed to enable the reader to assess whether the results are applicable to similar settings (Mays \& Pope 2000).

In line with Goetz \& LeCompte (1982), Morse (1999) and Horsborough (2003) find that situational rather than demographic representativeness is demanded - or in other words whether the developed theory may be "exported" to comparable situations. In the same vein, Kitto et al. (2008) describe conceptual generalizability and the transformation (the "export") to other health care contexts. This form of generalizability is not concerned with the collection of representative data, 
but rather with the researcher's analysis and interpretation of contexts in order to be able to predicate a theoretical understanding of the examined situation and field (Yin 1994). For the psychologist Amedeo Giorgi, this is a typification, which he chooses to call a general structure (Giorgi 1997). A chair, for instance, is a part of the furniture, while "furniture" typifies or indicates a general structure.

Concurring with Guba \& Lincoln (1981, 1982), Britten et al. (1995) indicated that similarities and differences must be identified before the relevance of an already studied setting can be assessed for other settings of interest.

Meta-synthesis represents another kind of generalization, but some researchers maintain that every part of a qualitative study is a unique representation of many realities, situations and truths. However, a number of methodological questions remain, such as whether it is possible to combine studies based on distinct qualitative methodologies (Flemming 2007).

The conclusion is that the mentioned methodological theorists agree that the question of research applicability is essential. They understand this to concern whether the results of the qualitative research can be matched, transformed or "exported" to comparable situations. This would require that we know what establishes a situation. It would also require an identification and clear description of similarities and differences between the various settings and - not least - of the multitude of individual and conceptual components of the entire research process, including the theoretical position, in particular if the quantitative tradition's requirement for replicability has to be met. But the pressing question would then be whether replicability as an important principle takes sufficient account of the differences in foundational problems that characterize the various paradigms.

Within the paradigm of qualitative research, allowing its strengths on its own terms, this article will illuminate ontological and epistemic questions encircling the answer to what establishes a situation and what counts as "generalizability" in qualitative research, or, in other words, what counts as replicability and applicability in qualitative research.

\section{Philosophical/theoretical sources}

In the exploration of what is involved in "generalizability" in qualitative research, I turn to two important sources, which each in their own way discuss ontological and epistemic questions about humans, society and science: Hans-Georg Gadamer's Wahrheit und Methode ((1960) 2004) and Bent Flyvbjerg's Making Social Science Matter (2001). Gadamer was a philosopher and the latter's work focuses on the study of humans and society. Apart from representing two different eras, their experiences are different with respect to the validity of research and the repositories of power in the scientific world. It could be said that Gadamer's philosophical interest is mainly the life world, while Flyvbjerg's predominant concern is with the development of methodology in the study of humans and society.

Although Flyvbjerg refers favourably to Gadamer's Wahrheit und Methode as an authoritative work, he points out the absence of a treatment of power. Some kind of knowledge translates into power, but we should make no mistake that power is also knowledge, as he repeatedly insists (Flyvbjerg 2001, p. 3), a point with which I concur. It is the powerful in society and in the different professional 
systems who identify what knowledge we need and thereby create the demand. A phenomenon that can be called King's evidence (Eriksson \& Nordman, 2004, p. 17).

A combination of some of Gadamer and Flyvbjerg's thinking seems to offer help with the exploration of the "generalizability" concept. In his chapter on "The power of example" Flyvbjerg summarizes (2001, ch. 6) five misconceptions, or oversimplifications, of the significance of the study of "single examples". He points out that although the study of single examples is often used for hypothesis generation in the preliminary phase of studies, it would be misleading to consider this type of study as a pilot study exclusively as a preparation for the real study, with its large-scale tests, systematic hypothesis testing and theory development (Ibid.). The whole point of his book is thus to rebut on ontological as well as epistemic grounds what he sees as a scientific misconception. From his position in science, Flyvbjerg's approach is to mediate between science and philosophy.

In contrast Gadamer saw his own attempt as a mediation between philosophy and science ((1960) 2004, p. 484) from a position in philosophy. In his "Preface to the second edition, 1965", he pointed out that the methodical spirit of science makes its mark everywhere - and to that extent, Gadamer recognized the necessity of methodical work in both what he calls the humanities and the established natural sciences (Ibid., pp. 474-483). This hardly concerns contradictions between methods, but it concerns epistemic objectives (Ibid., p. 475); that is the question of what we want to know something about, which comes before the research logic. In other words, hermeneutics understood as understanding and interpretation of the life world is relevant to the theory of science insofar as it uncovers what count as true knowledge, which does not lie in but before the research logic (Ibid., p. 485). In Gadamer's eloquent phrasing, the methodology battle conceals and misjudges what comes before science and research (Ibid., p. 475).

We see that both Gadamer and Flyvbjerg are concerned with ontological and epistemic problems. By thus applying and to some degree extending their discussion, we are able to approach the exploration of "generalizability" in qualitative research by taking an ontological and epistemic stance in relation to the four foundational problems, mentioned in the introduction. The first foundational problem leads to the other three foundational problems. In the following part the concept Science is synonymous with what Gadamer called the established natural sciences.

\section{Knowledge and its various forms}

Epistemology is the philosophy of how knowledge is acquired. While this is not meant as a new contribution to that discussion, it is recommended that researchers reflect on the following questions in preparation for the execution of a study:

1) What is the object/subject for the study? In addressing the question the researcher has to ask himself two basically different questions: What is the object of knowledge? Is it a study of physical objects; for example a study of biomechanical pain, the physiological development of headaches or the genetics of cancer cells? What is the subject of knowledge? Is it a study of humans and society; for example a study of life world phenomena expressed by the individual's deliberations, experiences, decisions and actions?

These questions take their point of departure in a difference between Science and the study of humans and society. In Science the body of knowledge is deep-rooted in an object. In the study of 
humans and society the body of knowledge is deep-rooted in a subject. A subject is changeable and connected to the life world and in relation to a context (Gadamer (1960) 2004, Flyvbjerg 2001). Therefore the ideal of predictability in Science and in the study of humans and society is challenged.

2) Is predictability the ideal? Keeping in mind the difficulty of controlling for confounding factors, the Science ideal of predictability cannot even be found in the Sciences - and thus, generalizability has its limits. While the study of biomechanical pain, the genetics of the cancer cell, etc., should be considered as Scientific studies with predictability as a primary aim - being always what they are, the scientist must throughout strive to eliminate bias and attempt to keep other factors constant.

The situation is different when researchers study phenomena expressed through humans and society. In such cases, researchers must accept that they have no way of knowing what determines what counts as experiences and actions. Flyvbjerg states that this will depend on the context (2001, p. 42). This is an important point; the meaning of context has concerned our culture since our Western way of being human was first defined in ancient Greece. A generation after Plato and Socrates, Aristotle suspected that something crucial had been let out of the Plato-Socrates model of knowledge with predictability as an ideal (Aristotle 1936, Dreyfus \& Dreyfus 1996). We also find detailed studies of human learning that indicate the meaning of context (Dreyfus \& Dreyfus 1986, Benner 1984). The Aristotelian concept phronesis with its context-dependent knowledge is introduced below.

3) Does the research unfold a practice context with changeable factors? The study of humans and society carries a humanistic legacy that changes with time, space, power and the context and relations in which they are studied. No researcher is therefore able to study humans and society without taking into consideration these factors, including the wider society and culture. Human deliberations, experiences, decisions and actions are changeable and particulars that will vary with time, space, relations, power. Thus the complexity of the studied context should not be eliminated or kept as constant factors; indeed, this would not be possible because the substance of the subject of knowledge (here understood as the changeable) is of a different nature than the object of knowledge in Science (being as it always is).

Where context plays a role in research, we are forced to be clear about the context and determine whether it is a practice context for a case-study or a qualitative empirical study involving individuals in a certain institutional context, or whether it is a historical or theoretical context. Just how wide or narrow is the context?

4) With a focus on epistemology - knowledge in its various forms and with a reading of Gadamer's "The topicality of Aristotelian hermeneutics" (2004, pp. 297-308) and Flyvbjerg's "Values in social and political inquiry" and "Empowering Aristotle" (2001, ch. 5, ch. 8) as contributions to our discussion, the following questions must also be asked: What are the constituents of knowledge and theory? What form of epistemic theory is best suited to elucidate human deliberations, experiences, decisions, actions?

Epistemic theory derives from what Aristotle understood as episteme. With the Aristotelian concept (intellectual virtue), episteme is generally understood as Science with its generalizable 
knowledge that holds true in all places and at all times and is invariable in time and space. The Aristotelian concept techne is thus art, a productive state that operates in the sphere of the variable. Phronesis as value-based knowledge has its sphere in particular circumstances, it is variable and depends on context (Aristotle 1936).

It is not my purpose to unfold the considerations further. But there is no escape from the language of the Hellenic inheritance. Episteme corresponds to the scientific ideal and epistemology as an expression of how any kind of knowledge is acquired. Phronesis does not exist in our language, so the intention here is to guide the qualitative researcher by asking the question: Are we trapped in the classical legacy, with the concept of episteme? For a researcher interested in the meaningfulness and significance of life in the form of human deliberations, experiences, decisions and actions, etc., valid research must be closely connected with phronesis (Delmar \& Johns 2008). We have to make clear the different intellectual virtues and expressions of different forms of human activity and epistemic interest. If epistemology is an expression of how any kind of knowledge is acquired, it explains the difficulty of liberating ourselves from the idea that there is no true knowledge if it is not replicable in all places and at all times. We need to accept that also context-dependent knowledge, with its different mode of expression, can offer us true understanding, but in another form of expression in its replicability and applicability.

\section{Properties of reality and the doubleness of the situation}

This foundational problem concerns the question of what establishes a situation. In line with Gadamer, we consider the question of truth conditions to come before the research logic. So rather than seeing the "generalizability" of qualitative studies as a methodological checking mechanism, we should perhaps see it as a property of reality and the doubleness of the situation as being both typical and unique. A question I already posed in my PhD dissertation (Delmar 1999).

The philosophy of our University Hospital is described by the words "The individual is like no others, like some others and like all others". This formulation may help towards understanding the following interpretation of the doubleness of a situation, in particular where context and situation are considered to play a role in the study of phenomena as they are expressed by the person's deliberations, experiences, decisions, and actions - in other words, research that regards people, context and situation as interconnected factors.

My discussion of this foundational problem draws on Løgstrup (Løgstrup 1986, 1997) although it also goes beyond him. Løgstrup gave a description of what characterizes a situation. But because I see people and situation as closely connected, I integrate the people in the situation; the people and the relations constitute the situation. Incidentally, this is compatible with Løgstrup's fundamental ideas (Ibid.).

A situation is characterised by its quality of doubleness; it is unique and typical at the same time. The situation is unique and exceptional because time is irreversible - the same situation will never occur again (ibid), and people with their unique stories and life world also constitute the uniqueness of the situation. But a situation is typical also in the sense that fundamental experiences can be found in every situation, according to Løgstrup (Ibid.), and typical phenomena can be found in every human being included in the situation. Such typical traits could for example be life phenomena such as hope, life courage, loneliness, the fear of death. It is thus in a person's life world 
phenomena that suffering is expressed (Delmar 2006, Delmar 1999). The typical is what we as people have in common. The human being is like all others and like some others as written in the philosophy of our University Hospital.

This is why typical traits and patterns can be identified in every situation; typical traits are always to be found in the people and the relations that make up the situation. For example when I read a story from Donald Duck for my 11-year-old son, he will enjoy it more if I name one of the characters after him. There are typical traits, something recognizable in every story with which he can identify. The human being is like all others and like some others. But because people are different, it is not only the irreversibility of time that makes the situation unique and exceptional. The typical traits in people and relations are expressed differently. The typical (and the universal) appears differently and in a variety of forms, among other things because people's life experiences are unique. A particular point of the uniqueness is the degree of depth. In an analysis of trust Løgstrup shows how a child's life may be permanently determined by the manner in which adults behave toward the child. Joy in living, the courage to be, insecurity can create experiences in the child that determine the uniqueness and actions of the individual (Løgstrup 1986, 1997)

To give an example of the doubleness; a study of the everyday lives of chronic sufferers found that the fear of death (a typical life phenomena in the study) is expressed in a variety of ways, even for persons who have suffered a blood clot in the heart. For the 40-year-old working father who collapsed in front of his three children, the experience is different than for the 70-year-old housewife whose responsibilities allow her to rest when the fear and tiredness comes back (Delmar et al. 2006, 2005).

While acknowledging that the study of phenomena expressed through people's deliberations, experiences, decisions and actions are contingent on time, space, relations, power and context (including society and culture), there will be typical traits and recognizable patterns - it is the experience from a similar situation that gives meaning. It is this recognisability that contributes to the "generalizability" of qualitative studies.

Please note that the formulation was "contributes to" generalizability. This is because recognisability in itself is not enough. It is only when the recipient of the new knowledge gives form to the recognizable and the typical by a practical transformation of the situation that recognisability has been accomplished. It is so to speak the relationship between the typical and the unique in the concrete situation in practice that must be brought into play. That is why we need to look at recognisability as a challenge to practice.

The general is thus what can be recognized across cases (i.e. communalities, similarities, differences in human beings/situations) and which thus becomes a challenge to practice (practical reasoning). A researcher should therefore ask questions throughout the entire analysis and interpretation process, such as: What is typical? How does it appear in this specific case? Is this recognizable? Is it meaningful for and in practice?

\section{How is understanding possible?}

Recognisability and the ability to understand the relevance for one's own practice is closely connected with the third foundational problem: Understanding - how is it possible? As with the 
question of knowledge and its forms, this is another of the great ongoing debates in philosophy. The intention is likewise that the researcher must become more conscious about the ontological and epistemic stance from and in which he works.

Understanding begins when something is speaking to us. It is in the very nature of human existence that humans and actions live their own lives and is not reduced to simplified objects. In its basic sense trust and respect are essential to any attempt to understand. Usually we trust one another with great reservation but if we really want to understand then openness for what we see and what we hear is required. (Løgstrup 1986, 1997)

There may be recognizable elements in the understanding but the essentially new and "strange" phenomenon has only been understood when it has entered into a relation with one's own practice - when, in other words, it is being applied. This is to say that the recognizable is seen in a new, unexpected and explanatory light.

In her article "The surgical nurse and the vulnerable patient", Kari Martinsen discusses the process of allowing memory to give its contribution when we are reminded of something; when one thing reminds us of another thing. I believe that this understanding of recollection fits our purposes here. Let me excerpt briefly:

"A connection is made when we are reminded of something else under the impression of one thing while something occurs to us, something we had not thought of before at all ... Memory ... let us become co-producers and creative ... Earlier sensory impressions make our memory recall knowledge that we already possess. By this recollection something may occur to us, and this is created by the recollection in the new situation" (Martinsen 2009, pp. 41-43).

Understanding begins with openness and goes on with recognisability created by the new situation. In a research context this requires reflection and interaction between open, creative and systematic reflection - which is no mean feat. It furthermore requires a confrontation with one's own prejudices so that the researcher actually brings his own preconceptions into question. This is something that many research projects could make more explicit.

In a confrontation with one's own prejudices, the time distance is significant (Gadamer 2004, pp. 283-284). Time distance is considered as a positive characteristic, when it enables us to distinguish among prejudices. The prejudices that make us too prejudiced and the prejudices where we realize (that they are) prejudices of a binding nature, where new knowledge makes sense to us and prepares us for changing current practices.

But full recognisability is possible only if we are courageous and ready to change practice. It is very much a question of power and whether our research produces the knowledge that the repositories of power demand. If the researcher does not produce the kind of knowledge that the powerful want to hear, will he be convincing and persistent enough to stand by his original ambition of changing or developing practice? Furthermore, the question is also how far the validity of an interpretation is accepted by practitioners (in their work), where interpretation is the explicit form of understanding. Any acceptance will typically appear in a contest with other interpretations, commitments and viewpoints (Flyvbjerg 2001, p. 139). 
Achieving understanding is thus possible only if the researcher allows himself to explicitly confront his own prejudices, a situation which makes the identified and recognizable (elements) appear in a new, unexpected but explanatory light. Furthermore, understanding is possible only if the validity of the interpretation is accepted by the practitioners or by the professional community in and of practice. Journal clubs have thus offered an appropriate forum for (the development of) a meaningful dialogue between the researcher, the newly developed knowledge and the professional practitioners, who will apply and accept the research in practice. Power must be handed back to practice. This presents a big challenge for future researchers and will demand work on several fronts in close, daily contact with the practitioners who want to contribute to the development and application of high-quality research findings.

\section{The researcher's role: What are the fundamental questions that the researcher must ask before a study is designed?}

The three previously discussed foundational problems prepare the ground for the fourth, which subsumes the other three in its concern with the researcher's understanding of his own role. This foundational problem is one that Flyvbjerg in particular emphasizes:

"Today's researchers seldom make explicit which one of these three roles (episteme, phronesis, techne) they are practicing. The whole enterprise is simply called "science", even though we are dealing with quite different activities" (Flyvbjerg 2001, p. 61).

So the first precondition for valid research is that the methodology and the method are adapted to the matter under examination, a researcher thus needs to be open to deliberate on the following questions, summarizing the three previously foundational problems:

1. What is the object/subject of knowledge that I want to study?

2. Within what knowledge understanding do I place myself - episteme, techne, phronesis?

3. How do I view the connection between philosophy, Science and the study of humans and society? Philosophy can help us understand the phenomena and the life world, the study of humans and society can help us to develop the context-depended knowledge and Science can explain and approximately predict the physical objects.

4. In my research, do I work on the basis of premises dictated by reality and Science rather than on the study's own premises?

5. What is my understanding of reality and the concrete situation?

6. How is my power, the repositories of power and the dialogue with practice?

It may be asked why it should be necessary to pose and reflect on ontological and epistemic questions and why it should be necessary at all to thematize "generalizability" in qualitative research? The answer is that as a credible and serious research worker, one has to be clear about the importance of this comprehensive reflection for one's own research work, and thus for the 
community of researchers: What is knowledge and in what knowledge context do I place myself what kind of interest drives this study, what kind of human activity do I want to explore?

It is paramount that the researcher is very conscious about his ontological and epistemological position that he carries with him into the research endeavour. This also involves further questions such as:

- in what research tradition was I trained?

- would I be able and ready to let go of parts of this tradition should it not fit with the intellectual interest I want to pursue in my research?

- if other intellectual interests dominate where I work, would I be ready to maintain my stand?

- or would I rather accept poor research work and hope that my colleagues will never find out? It is clear that it will be discovered only if one's fellow researchers ask the kind of questions that come before the research logic.

- with respect to the researchers who are concerned with the study of causal regularities, do the qualitative researchers develop methodological guidelines for the study of humans and society? Do we actually ask those questions that come before the research logic?

\section{Discussion}

For a researcher who is interested in the meaningfulness and significance of life in the study of humans and society, it is particularly important that qualitative research is allowed to develop on its own terms. On the basis of my discussion of four foundational problems, the intention here has been to guide the qualitative researcher by asking questions that may lead to an exploration of criteria for "generalizability" in qualitative research.

I will leave it to the researcher community to decide if the standard of replicability upheld by the quantitative tradition should be totally discarded in the qualitative tradition. If the community chooses to maintain replicability as a standard, this article's answer to the question of what counts as replicability and applicability will be that "generalizability" in qualitative research builds on recognisability (i.e. communalities, similarities and differences in situations and human beings) and challenges to practice as practical reasoning.

On the basis of Gadamer's and Flyvbjerg's requirements for a clear description of the entire research process, our discussion of the foundational problems enables us to deduce that time, space, relations, power and context determine a situation and that they therefore play a special role in qualitative studies. As any situation can be said to be typical and unique at the same time, recognisability appears by looking for communalities, similarities and differences. These aspects were also indicated to be important factors by earlier methodological workers (Guba \& Lincoln 1981, 1982; Bitten et al. 1995). But this can only form part of the "generalizability" of a finding; knowledge should be recognized and confirmed by others - e.g. through their acceptance of it as a useful solution or a practical way of reasoning. Only when the recipient of new knowledge is able to handle the relationship between the recognizable or typical, and the unique, and relate it to his 
own practice, only then does it make sense to him, and the road is clear for understanding and practical application of the new knowledge. As mentioned in the background section's discussion of methodology, the issue of research applicability is a shared and essential concern among methodological theorists. This article has attempted to view the question of replicability and practical application as a foundational problem and to discuss how understanding is possible along with the readiness to change. It is the close dialogue with the practice field and its participants that poses the big challenge of the future.

\section{Conclusion}

We have found that "generalizability" in qualitative research builds on recognisability and a challenge to practice. The present deliberations, not least with their emphasis on the dialogue with practice and the making explicit of the researcher role, should be brought to bear on future project descriptions. In the endeavour to further qualify research that aims to study people's deliberations, experiences, decisions and actions, it seems obvious that the researcher describes the ways in which new knowledge is imagined to be developed in collaboration with practice and how power is to be handed back to practice. It is likewise important that the researcher makes explicit his own role and understanding of knowledge.

\section{References}

Aristotle. Ethica Nicomachea. Translated by Niels Møller. Copenhagen: Levin \& Munksgaard, 1936, pp. 145-166.

Benner P. From Novice to Expert. Excellence and power in Clinical Nursing Practice. California; AddisonWesley Publishing Company, 1984.

Britten N, Jones R, Murphy E, Stacy R. Qualitative research methods in general practice and primary care. Family practice, 1995, 12 (1): 104-114.

Creswell, J. W. Research design: Qualitative, quantitative, and mixed methods approaches, 2 edn, Sage Publications, Thousand Oaks, 2003.

Delmar C. Tillid \& Magt - en moralsk udfordring [Trust \& Power - a moral challenge]. Copenhagen: Munksgaard, 1999.

Delmar C, Bøje T, Dylmer D, Forup L, Jakobsen C., Møller M., Sønder H., Pedersen BD. Achieving harmony with oneself: life with a chronic illness. Scand J Caring Sci; 2005; 19 (3): 204-212.

Delmar C, Bøje T, Dylmer D, Forup L, Jakobsen C, Møller M, Sønder H., Pedersen BD. Independence/Dependence - A Contradictory Relationship: Life with a Chronic Illness. Scand J Caring Sci; 2006; 20 (3): 261-268.

Delmar C. The phenomenology of life phenomena - in a nursing context. Nursing Philosophy; 2006; 7 (4): 235-246.

Delmar C, Johns C. The Good, the Wise and the Right Clinical Nursing Practice, Aalborg: Aarhus University Hospital, 2008. www.foksy.dk. 
Dreyfus H, Dreyfus S. Mind over Machine. The Power of Human Intuition and Expertise in the Era of the Computer. New York: Free Press, 1986.

Dreyfus HL. Dreyfus SE. The relationship of theory and practice in the acquisition of skill. In: Benner P, Tanner CA, Chesla CA.(ed.). Expertise in Nursing Practice. Caring, Clinical Judgment and Ethics. New York: Springer Publishing Company, 1996: 29 - 47.

Eriksson E, Nordman T. Den Trojanska Hästen II. Utvecklandet av evidensbaserade vårdande kulturer [The Trojan Horse II. Development of evidence-based caring cultures]. Vasa: Institutionen för vårdvetenskap, Åbo Akademi, 2004.

Flemming K. The synthesis of qualitative research and evidence-based nursing. Evid Based Nurs; 2007; 10: 68-71.

Flyvbjerg B. Making Social Science Matter. Why social inquiry fails and how it can succeed again. Cambridge: Cambridge University Press, 2001.

Gadamer HG. Wahrheit und Methode (1960), translated into English as Truth and Method by W. GlenDoepel (1975), translated into Danish as Sandhed og metode. Grundtræk af en filosofisk hermeneutik. by Arne Jørgensen, 1st Ed. Århus: Systime, 2004.

Giorgi A. The theory, practice and evaluation of the phenomenological method as a qualitative research procedure. Journal of Phenomenological Psychology, 1997, 28 (2):235-260.

Guba EG, Lincoln YS. Effective evaluation: Improving the usefulness of evaluation results through responsive and naturalistic approaches. San Francisco, CA: Jossey-Bass, 1981.

Guba EG, Lincoln YS. Epistemological and methodological bases of naturalistic inquiry. Educational Communication and Technology Journal, 1982; 30 (4): 233-252.

Horsburgh D. Evaluation of qualitative research. Journal of Clinical Nursing, 2003; 12: 307-312.

Kitto SC, Chesters J, Grbich C. Quality in qualitative research. Criteria for authors and assessors in the submission and assesment of qualitative research articles for The medical Journal of Australia. MJA, 2008; 188 (4): 243-246.

LeCompte MD, Goetz JP. Problems of Reliability and Validity in Ethnographic Research, Review of Educational Research, 1982; 52: 31-60.

Løgstrup KE. Den Etiske Fordring 11th Ed. Copenhagen: Gyldendal, (1956) 1986 Translated into English as The Ethical Demand by Hans Fink \& Alasdair MacIntyre. London: University of Notre Dame Press, 1997.

Martinsen K. Operasjonssykepleien og den sårbare pasienten. Kropp, sansning og urørlighetssone [The surgical nurse and the vulnerable patient. Body, sensory perception and the untouchability 
Qualitative Studies, 1(2)

zone]. In: Davøy GM, Eide PH, Hansen I. Operasjonssykepleie, Oslo: Gyldendal Akademisk, 2009, pp. $32-48$.

Mays N, Pope C. Qualitative research in health care. Assessing quality in qualitative research. $B M J$, 2000; 320: 50-52.

Morse J. Qualitative Generalizability. Qual Health Res, 1999; 9: 5-6.

Schoefield JW. Increasing the Generalizability of Qualitative Research. In: Huberman, AM, Miles MB (Eds.) The Qualitative Researcher's Companion. California, Sage Publications Inc., 2002: 171-205.

Stake RE. The case study method in social inquiry. Educational Researcher, 1978; 7(2), 5-8.

Wheeldon J. Mapping Mixed Methods Research: Methods, Measures, and Meaning. Journal of Mixed Methods Research 2010; 4: 87 - 102.

Yin R.K. Case study research. Thousand Oaks, CA: Sage, 1994

\section{Author}

Charlotte Delmar, PhD, Cand. Cur. is Director of the Research Unit for Clinical Nursing at Aarhus University Hospital, Aalborg. Email: c.delmar@rn.dk 